\title{
DAS ILHAS AO CONTINENTE: ESTRATÉGIAS DE INSERÇÃO SOCIAL DOS IMIGRANTES AÇORIANOS NA POVOAÇÃO DE SANTO AMARO, RS, ATRAVÉS DOS REGISTROS BATISMAIS (1757-1774).
}

\section{Alexandra Lis Alvim ${ }^{1}$}

Esta pesquisa foi apenas um exercício de aproximação com algumas informações que podem ser extraídas de um livro de registros de batismais setecentista. Os registros paroquiais constituem-se em uma fonte valiosa para o conhecimento de sociedades de Antigo Regime. A Igreja, ao querer saber o "estado de suas almas", recolhia com alguma frequência informações sobre a vida de seus fieis de forma individualizada. Momentos importantes, como nascimentos, casamentos e mortes ficaram registrados em seus arquivos, dando-nos conhecimento sobre uma boa parte daquela sociedade, já que estes registros abrangeram também aqueles que, por não disporem de muitos recursos, não puderam deixar muitos vestígios de suas existências.

Nesta pesquisa foram analisados os registros batismais de um

${ }^{1}$ Graduada em Licenciatura em História pela Universidade Federal do Rio Grande do Sul. Monografia orientada pelo Prof. Dr. Fábio Kühn (UFRGS). 
dos três livros da freguesia de Bom Jesus do Triunfo ${ }^{2}$, da Capitania do Rio Grande de São Pedro, atual estado do Rio Grande do Sul. A freguesia do Padre Tomás Clarque possuiu em seus primeiros anos de existência um livro dedicado à população branca, outro à escrava e outro para os ilhéus assentados na Tranqueira de Santo Amaro, povoação que lhe pertencia. Os registros batismais funcionavam, para a época, quase como documentos de identificação, registrando o nome do individuo batizado, o mês, o ano, quem havia batizado, quem eram os pais, se eram casados ou não, quem eram os avós, a origem de pais e avós, quem eram os padrinhos e quaisquer outras peculiares que o pároco considerasse importante. No livro de Santo Amaro, 61,44\% dos pais dos batizados foram declarados como "Casal Del-Rey assistente na Tranqueira de Santo Amaro" - denominação que indicava pertencerem a uma política migratória da Coroa Portuguesa que consistia em promover o deslocamento de famílias das ilhas dos Açores para regiões de fronteira de seu império ultramarino.

O objetivo da monografia, intitulada "Das ilhas ao Continente: estratégias de inserção social dos imigrantes açorianos na povoação de Santo Amaro, RS, através dos registros batismais (1757-1774)" foi

\footnotetext{
${ }^{2}$ Livro 1 - A de Batismos de Triunfo (1757 - 1774) - AHCMPA (Arquivo Histórico da Cúria Metropolitana de Porto Alegre).
} 
Revista Vernáculo, $n^{o} 29,1^{o}$ sem/2012

entender como estes imigrantes utilizaram o compadrio, isto é, a família ritual que surgia no sacramento do batismo, como estratégia de criação ou reiteração de vínculos sociais ${ }^{3}$. O período estudado foi o período abrangido pelo livro, que correspondeu ao início das atividades da paróquia ao momento em que Santo Amaro foi desmembrada de Triunfo e transformada em freguesia. O livro conta com 175 registros de batismo, sendo que em 126 destes consta a classificação de "Casais Del-Rey".

O primeiro capítulo discorreu um pouco a cerca da imigração açoriana e do surgimento de Santo Amaro. As ilhas dos Açores desde muito cedo contribuíram para o processo de colonização da América Portuguesa, fosse como entreposto entre o velho e o novo continente,

${ }^{3}$ A noção de "relações de compadrio" foi extraída das seguintes obras: BRÜGGER, Sílvia Maria Jardim. Minas Patriarcal: família e sociedade (São João DEl Rei Séculos XVIII e XIX). São Paulo: Annablume, 2007. BERTRAND, Michel. "De la familia a la red de sociabilidad". Revista Mexicana de Sociología, vo.61, n², 1999. HAMEISTER, Martha D. Para Dar Calor à Nova Povoação: estudo sobre estratégias sociais e familiares a partir dos registros batismais da Vila de Rio Grande (1738 1763). Rio de Janeiro: UFRJ - Programa de Pós-Graduação em História Social, 2006 (Tese de Doutorado). RAMOS, Donald. Teias sagradas e profanas: o lugar do batismo e compadrio na sociedade de Vila Rica durante o século do ouro. Varia Historia [S.I.], n.31,p.41-68,2004. VENÂNCIO, Renato Pinto. Redes de compadrio em Vila Rica: um estudo de caso. IN: OLIVEIRA, Mônica Ribeiro \& ALMEIDA, Carla Maria Carvalhoi. EXercícios de Microhistória. Rio de Janeiro. Editora FGV, 2009. 
ou com a participação de soldados e famílias ${ }^{4}$. Diversos problemas estruturais internos fizeram da emigração de seus excedentes populacionais um fator recorrente na história do arquipélago. A "política de casais" ${ }^{5}$ foi um expediente desenvolvido ao longo do tempo pela Coroa Portuguesa visando utilizar este excedente em lugares estratégicos do seu vasto império ultramarino - como o Rio Grande de São Pedro que, às vésperas das desmarcações do Tratado de Madrid, necessitava de gente que povoasse seu interior, ocupando o território dos Missões Jesuíticas Orientais, que seriam recebidos da Coroa Espanhola. No contexto destas demarcações foi fundada Santo Amaro, entreposto militar nas margens do rio Jacuí, caminho entre os Campos de Viamão e os Sete Povos e onde algumas famílias de ilheus se alojaram "provisoriamente" enquanto esperavam a demarcação de suas

\footnotetext{
${ }^{4}$ José Damião Rodrigues discorreu sobre este assunto em dois artigos utilizados nesta monografia: RODRIGUES, J.D. Entre duas margens: a circulação atlântica dos açorianos nos séculos XVII e XVIII. Arquipélago-história, Ponta Delgada, 2a série, vol. VI, 2002. E o artigo de Carlos Cordeiro e Artur Boavida Madeira: CORDEIRO, C., MADEIRA, A.B. A emigração açoriana para o Brasil (1541-1820): uma leitura em torno de interesses e vontades. Arquipélago-história, Ponta Delgada, $2^{a}$ Série, vol. VII, p.99 - 122.2003

${ }^{5}$ Segundo Queiroz, a expressão "casais" ou "casais de número" já era adotada na Vila do Rio Grande de São Pedro desde 1738 para referir-se aos casais de povoadores imigrantes de outras partes do Brasil que eram registrasos nos Livros de Matrícula da povoação para serem ajudados pela Fazenda Real. QUEIROZ, Maria Luiza Bertuline. A Vila do Rio Grande de São Pedro (1737-1822). Rio Grande: FURG, 1987.
} 
terras, adiada com a recusa indígena de abandonar o território missioneiro. Trabalhos recentes ${ }^{6}$ sobre a temática têm demonstrado que estes imigrantes, que na época representaram um significativo acréscimo demográfico ao Continente, não constituíam um grupo homogêneo. Ainda que muitos dependessem da ajuda da Fazenda Real, traziam hierarquias, e até recursos, das Ilhas, que distinguiam um dos outros.

Santo Amaro localizava-se nas terras de Francisco Xavier de Azambuja. Francisco era um dos muitos genros de Jerônimo de Ornelas que possuíam sesmarias na região. No segundo capítulo, discorreu-se sobre a importância do sacramento do batismo para aquelas sociedades. O significado da palavra em grego remonta a ideia de "imersão" imersão de um indivíduo nas águas batismais e na comunidade religiosa - condição sine qua non para adentrar por inteiro na sociedade lusa setecentista ${ }^{7}$. Através dele as famílias inseriam seus rebentos na comunidade terrena e espiritual que formava uma paróquia. Estabeleciase naquele momento uma família ritual, por meio do compadrio,

${ }^{6}$ HAMEISTER, op.cit. COMISSOLI, Adriano. Do Arquipélago ao Continente: Estratégias de sobrevivência e ascensão social na inserção social açoriana nos Campos de Viamão (Séc. XVIII). AEDOS - Revista do Corpo Discente do Programa de PósGraduação em História da UFRGS, Porto Alegre, v.2, n.3.Disponível em: http://seer.ufrgs.br/aedos/article/view/10584 (acessado em 01 de outubro de 2012).

${ }^{7}$ HAMEISTER, op. cit, p. 189. 
tecendo vínculos que ultrapassavam a morte e seriam carregados até o Juízo Final. Na pia batismal, os padrinhos tornavam-se fiadores do batizado perante Deus, assumindo a condição de zelar por sua alma, o que, na prática, também poderia significar uma proteção ao longo de sua vida.

Tem-se demonstrado que o compadrio poderia ser utilizado de duas formas: para estabelecer vínculos verticais, adentrando na parentela espiritual de famílias importantes; e ou vínculos horizontais, reiterando e sacramentando afinidades com participantes do mesmo grupo social. Através de seu estudo, é possível tentar entender como os ilheus preferiam utilizá-lo, fosse atando laços espirituais que recordavam as Ilhas e a trajetória até o Continente, ou fosse atando laços com os senhores e importantes do lugar novo ${ }^{8}$. No terceiro capítulo buscou-se conhecer um pouco das opções de compadrio que os Casais del-Rey de Santo Amaro escolheram. Para isso, foram cruzados alguns dados contidos o "Rol de Confessados da nova paróquia do Bom Jesus do Triunfo no ano de 1758", os Autos de Justificação de Matrimônio (1753-1763) ${ }^{9}$ e o trabalho genealógico sobre os primeiros

\footnotetext{
${ }^{8}$ HAMEISTER, op. cit, p.346.

9 "Rol de Confessados da nova paróquia de Bom Jesus do Triunfo no ano de 1758" (AHCMPA - Arquivo Histórico da Cúria Metropolitana de Porto Alegre) e "Autos de Justificação de Matrimônio (1753-1763)" (AHCMPA).
} 
povoadores de Triunfo de José de Araújo Fabrício ${ }^{10}$.

Os dados do livro demonstraram que a população inicial do povoado não parecia ser tão homogênea quanto se suporia de uma comunidade na qual a historiografia e memória popular tenderam a tratar como "tipicamente açoriana". Somando-se os 83 pais com as 83 mães, constatou-se que, num total de 166 pessoas, 12,65\% não eram das ilhas. Destes 83 núcleos familiares, 51 pais e mães constam como Casais de Sua Majestade. Somando todos os pais e mães do registro, ou seja, 166 pessoas, verificou-se que 47,05\% tinham uma mesma procedência, a Ilha de São Jorge, dos Açores. Em 47,1\% dos seus registros, os Casais de Sua Majestade assistentes na Tranqueira de Santo Amaro optaram por tornarem-se parentes espirituais de pessoas importantes do lugar, como militares e fazendeiros. Outros 35,5\% preferiram escolher seus compadres dentro do próprio grupo que aguardava a demarcação das terras.

${ }^{10}$ FABRÍCIO, José de Araújo. A Freguesia de Nosso Senhor Bom Jesus de Triunfo. Revista do Instituto Histórico e Geográfico do RS, v.27, n.1-4 (1947), p.318-323. 
Revista Vernáculo, $n^{\circ} 29,1^{\circ}$ sem/2012

Gráfico 1 - Tipos de compadrio observados nos Casais de Sua Majestade de Santo Amaro

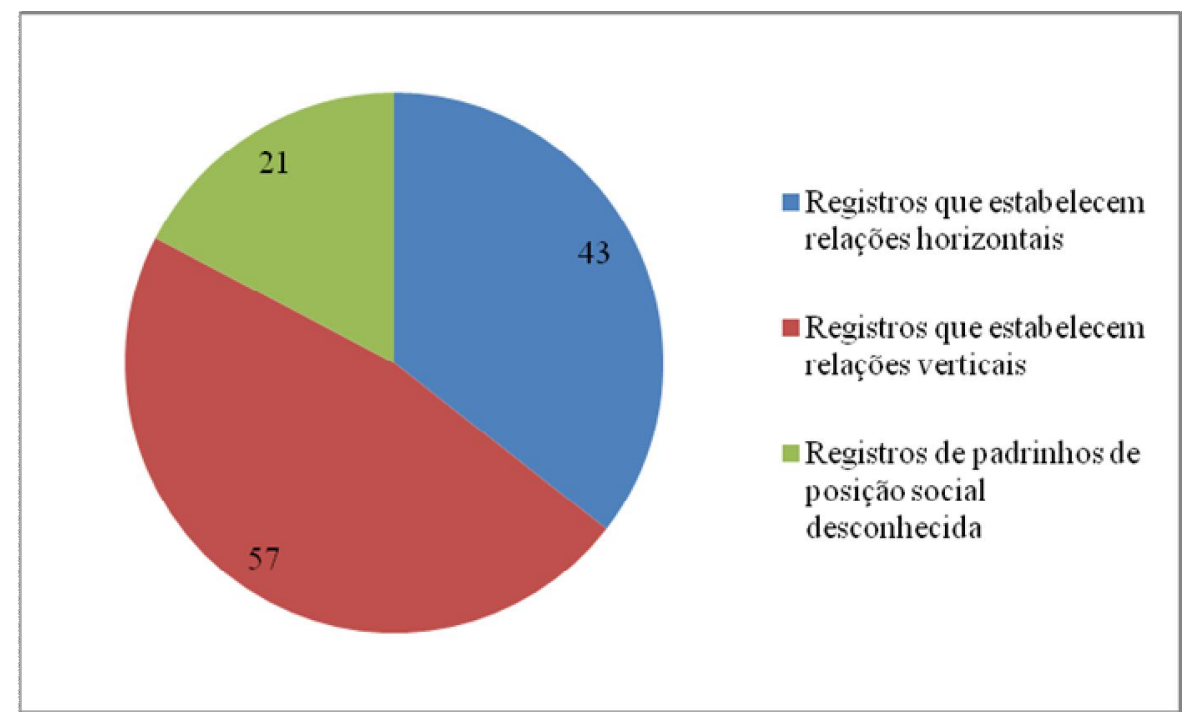

$\mathrm{Na}$ condição de arranchados as margens de um rio com muitas estâncias e poucas povoações, a concentração de um grupo de pessoas de procedência semelhante e um número elevado de casais inscritos como "Casais de Sua Majestade" parece ter criado condições ideais para o surgimento de uma identidade fortemente vinculada às Ilhas. $\mathrm{O}$ livro de batismos que o Padre Clarque criou especificamente para esta comunidade pode ser entendido como um reflexo do espaço que estes homens ocuparam nas complexas hierarquias sociais da Época Moderna - não eram nem escravos, nem das gentes povoadoras do lugar, mas não estavam isentos de trazerem consigo as hierarquias que sustentavam 
suas vidas nas Ilhas, que poderiam facilitar a obtenção de recursos ou o relacionamento com as famílias dos poderosos.

Esta pesquisa, primeira aproximação com este tipo de fonte, esbarrou na dificuldade em entender a natureza de tantas relações e hierarquias observadas nas fontes consultadas e na facilidade de perderse num mar de nomes com poucos sobrenomes e informações. Da leitura do livro de registros ficaram mais perguntas que respostas. A igreja matriz, construída cerca de uma década depois do fim do livro de registros, e as casinhas antigas de Santo Amaro do Sul, hoje distrito do município de General Câmara, são testemunhas deste passado onde a religião ajudava a criar e recriar constantemente modos de sociabilidade em suas cerimônias de batismo e casamento, em suas missas de domingo, nas festas dos santos e nas cerimônias de morte, significando e ressignificando suas vidas.

\section{BIBLIOGRAFIA}

BERTRAND, Michel. De la familia a la red de sociabilidad. Revista Mexicana de Sociología, vol. 61, n 2, abril-junio, 1999, México. 
Revista Vernáculo, $n^{\circ} 29,1^{\circ}$ sem/2012

BRÜGGER, Sílvia Maria Jardim. Minas Patriarcal: família $e$ sociedade (São João Del Rei -Séculos XVIII e XIX). São Paulo: Annablume, 2007.

CESAR, Guilhermino. História do Rio Grande do Sul. Porto Alegre: Editora Globo, 1970. (Coleção Província).

COMISSOLI, Adriano. Do Arquipelágo ao Continente: Estratégias de sobrevivência e ascensão social na inserção social açoriana nos Campos de Viamão (Séc. XVIII). AEDOS - Revista do Corpo Discente do Programa de Pós-Graduação em História da UFRGS, Porto Alegre, v.2, n.3. Disponível em: <http://seer.ufrgs.br/aedos/article/view/10584> (acessado em 01 de outubro de 2012).

CORDEIRO, C., MADEIRA, A. B. A emigração açoriana para o Brasil (1541-1820) : uma leitura em torno de interesses e vontades, Arquipélago-história, Ponta Delgada, 2a Série, vol.VII, p. 99-122. 2003. Disponível em: <http://repositorio.uac.pt/bitstream/10400.3/384/1/Carlos_Cordeiro_p9 9-122.pdf> (acessado em 01 de outubro de 2012).

FABRÍcIO, José de Araújo. A Freguesia de Nosso Senhor Bom Jesus de Triunfo. Revista do Instituto Histórico e Geográfico do RS, v.27, n.1-4 (1947), pag. 318-323.

HAMEISTER, Martha D. Para Dar Calor à Nova Povoação: estudo sobre estratégias sociais e familiares a partir dos registros batismais da Vila de Rio Grande (1738 - 1763). Rio de Janeiro: UFRJ - Programa 
Revista Vernáculo, $n^{\circ} 29,1^{\circ}$ sem/2012

de Pós-Graduação em História Social, 2006 (Tese de Doutorado).

RODRIGUES, J.D. Da periferia insular às fronteiras do império: colonos e recrutas dos Açores no povoamento da América". Anos 90, Porto Alegre, v. 17, n. 32, p. 17-43, dez. 2010

. Entre duas margens: a circulação atlântica dos Açorianos nos séculos XVII e XVIII, Arquipélago-história, Ponta Delgada, 2a Série, vol. VI, p. 225-245. 2002. Disponível em: <http://repositorio.uac.pt/bitstream/10400.3/370/1/Jos\%C3\%A9_D_Ro drigues_p2-245.pdf> (acessado em 01 de outubro de 2012).

RAMOS, Donald. Teias sagradas e profanas: o lugar do batismo e compadrio na sociedade de Vila Rica durante o século do ouro. Varia História [S.I.], n. 31, 2004, p. 41-68.

VENÂNCIO, Renato Pinto. Redes de compadrio em Vila Rica: um estudo de caso. IN:OLIVEIRA, Mônica Ribeiro \& ALMEIDA, Carla Maria Carvalho. Exercícios de Microhistória. Rio de Janeiro. Editora FGV, 2009. 